Revista Tecnologia e Sociedade, Curitiba, v. 11, n. 23, 2015

ISSN (versão online): 1984-3526

ISSN (versão impressa): 1809-0044

\title{
A definição da frequência de geração da UHE de Itaipu: trajetórias e controvérsias sociotécnicas
}

\author{
The definition of Itaipu hydroelectric dam's electric frequency: trajectories and \\ sociotechnical controversies
}

\author{
Catiane Matiello ${ }^{1}$ \\ Gilson Leandro Queluz ${ }^{2}$
}

Artigo submetido em jan./2015 e aceito para publicação em abr./2015.

\section{RESUMO}

Este artigo examina o fechamento de controvérsias sociotécnicas na trajetória de implantação da usina hidrelétrica de Itaipu. A análise se concentra no processo de definição da frequência elétrica em que a geração da usina ocorreria, considerando a diferença entre os padrões adotados no Brasil e no Paraguai e a divisão da energia produzida pela usina entre os dois países. A abordagem metodológica consiste em pesquisa bibliográfica e análise documental, com base nos fundamentos do campo de estudos em Ciência, Tecnologia e Sociedade (CTS). Observou-se como os grupos sociais envolvidos criaram soluções técnicas, como as interpretaram dentro do contexto maior de implantação da usina e de que forma as estabilizaram compondo um arranjo com implicações na constituição de um novo sistema.

Palavras-chave: Estudos CTS; História social da tecnologia; Usina hidrelétrica de Itaipu; Controvérsias sociotécnicas

\section{ABSTRACT}

This article examines the closure of socio-technical controversies in the implantation of the Itaipu hydroelectric dam. The main focus of the analysis is the process of deciding in which electric frequency standard the power plant would operate, considering the different standards adopted by Brazil and Paraguay and the distribution of the energy produced between both countries. The methodology consists of bibliographic research and documental analysis, based on the fundamental concepts of Science, Technology and Society (STS) studies. It has been observed how involved social groups have created technical solutions, interpreted them within the larger context of the implementation of the dam, and how they stabilized that solutions, thus composing an arrangement that has implications in the constitution of a new system.

Key-words: STS Studies; Itaipu hydroelectric dam; socio-technical controversies; Social history of technology

\footnotetext{
${ }^{1}$ Graduada em História pela Universidade Estadual de Ponta Grossa (UEPG) e Mestre em Tecnologia pelo Programa de Pós-Graduação em Tecnologia (PPGTE), da Universidade Tecnológica Federal do Paraná (UTFPR). Doutoranda em Tecnologia na linha de pesquisa Tecnologia e Trabalho pelo PPGTE/UTFPR com bolsas da Coordenação de Aperfeiçoamento de Pessoal de Nível Superior (CAPES) e da Fundação Araucária. catimatiello@hotmail.com

${ }^{2}$ Graduado em História pela Universidade Federal do Paraná (UFPR), Mestre em História pela Universidade Federal do Paraná (UFPR) e Doutor em Comunicação e Semiótica pela Pontifícia Universidade Católica de São Paulo (PUC/SP). Pós-Doutor em Política Científica e Tecnológica pelo Departamento de Política Científica e Tecnológica (DPCT), da Unicamp e professor da UTFPR no Departamento de Estudos Sociais e no PPGTE. queluz@utfpr.edu.br
} 
Revista Tecnologia e Sociedade, Curitiba, v. 11, n. 23, 2015

ISSN (versão online): 1984-3526

ISSN (versão impressa): 1809-0044

\section{INTRODUÇÃO}

O processo de projetamento, construção e implantação de hidrelétricas guarda interações complexas com os contextos políticos, sociais, ambientais e técnicos nos quais se constitui e por isso atua de maneira específica na criação de novas relações na sociedade, conformando recortes privilegiados para análises sob a dimensão sociotécnica.

O caso da usina hidrelétrica de Itaipu representa um capítulo importante na história das barragens no Brasil. $O$ desenvolvimento de um projeto de aproveitamento hidrelétrico do rio Paraná exigiu centenas de estudos e a elaboração de diversas alternativas, numa trajetória marcada por controvérsias em termos técnicos, políticos, econômicos, culturais, ambientais e sociais.

Nesse sentido, o presente artigo procura desnaturalizar um dos processos constituintes da trajetória sociotécnica3 da usina, concentrando-se na história da definição da frequência em que sua geração ocorreria. Tendo em vista que o padrão adotado no Brasil é o de 60 hertz ( $\mathrm{Hz}$ - ciclos/segundo) e o do Paraguai $50 \mathrm{~Hz}$ e que a energia produzida pela usina, de acordo com o Tratado de Itaipu, seria dividida meio a meio entre os dois países, com o excedente paraguaio sendo vendido ao Brasil, um intenso debate entre os dois países foi estabelecido em busca de uma solução técnica e política. Neste cenário procuraremos observar os valores e as questões levantadas pelos grupos envolvidos, as relações que apontam os atores chamados a participar do processo, as instâncias em que as decisões técnicas se deram e a construção de critérios para elaboração de alternativas, a partir de questões políticas.

Partimos do marco teórico composto pelo campo de estudos em Ciência, Tecnologia e Sociedade (CTS) para assumir como premissa uma concepção de tecnologia que a considera como construção social, em cujo desenvolvimento estão presentes opções por formas de relações culturais, políticas e econômicas. Compreendemos que decisões técnicas são também decisões políticas e que "tecnologia" e "sociedade" constituem-se simultânea e mutuamente, de modo que algo não possa ser considerado estritamente tecnológico ou inversamente não tecnológico.

Portanto, na seção a seguir apresentamos o resultado de pesquisa

\footnotetext{
${ }^{3}$ Sobre o conceito de trajetória tecnológica ver: Thomas (2008).
} 
Revista Tecnologia e Sociedade, Curitiba, v. 11, n. 23, 2015

ISSN (versão online): 1984-3526

ISSN (versão impressa): 1809-0044

bibliográfica, que trará a visão de autores que se dedicaram a abordar, sobre diversos vieses, a história da usina, e de seu cotejamento com documentos oficiais e matérias jornalísticas do período. Essa análise é pautada pelos fundamentos do campo de estudos em Ciência, Tecnologia e Sociedade (CTS), de modo a orientar a observação da tecnologia em sua elaboração, especialmente sob a compreensão de que decisões técnicas são também decisões políticas e que "tecnologia" e "sociedade" constituem-se simultânea e mutuamente ${ }^{4}$.

\section{O PROCESSO DECISÓRIO EM TORNO DA QUESTÃO DA FREQUÊNCIA}

A frequência elétrica é uma grandeza física dada em Hertz $(\mathrm{Hz})$, que define o número de ciclos que a corrente elétrica completa em um determinado tempo. A definição da frequência da rede tem implicações nos equipamentos vinculados à geração, nas redes de transmissão e nas máquinas alimentadas pela energia. A controvérsia envolvendo a frequência em Itaipu se desdobrou a partir da diferença de operação das redes elétricas dos dois países sócios, com o padrão brasileiro sendo o de $60 \mathrm{~Hz}$ e o do Paraguai, $50 \mathrm{~Hz}$. Os debates que se desenvolveram em torno da necessidade de um fechamento para o problema configuraram um momento importante da implantação da usina, pois reabriram questões políticas, econômicas e sociais, que pareciam solucionadas com o Tratado de Itaipu, além de colocar novos itens em pauta nas discussões.

O anexo "B" do Tratado de Itaipu, assinado em 1973, foi redigido com base em um relatório preliminar entregue pela Comissão Mista Técnica aos governos brasileiro e paraguaio em janeiro do mesmo ano e tinha como objetivos descrever e identificar as partes principais do projeto da hidrelétrica, definindo o arranjo geral da usina e do reservatório e as funções dos elementos que compõe o conjunto (SÓRIA, 2012, p. 86). Em sua terceira parte, a redação do ponto relativo à questão da frequência não estabeleceu nenhuma definição ${ }^{5}$. $O$ engenheiro Mário Pena Bhering, que participou das negociações que culminariam no Tratado de Itaipu, afirmou: "Não tínhamos precisão do que iria acontecer com a frequência ou ciclagem. $\mathrm{Na}$ velocidade com que as coisas foram acontecendo, chegou-se a um ponto em que, se fôssemos discutir a ciclagem antes, não se assinaria o Tratado com o Paraguai.

\footnotetext{
${ }^{4}$ Ver especialmente, sobre as relações entre tecnologia e sociedade, Feenberg (2010). Sobre as controvérsias sociotécnicas e os conceitos de flexibilidade interpretativa, fechamento e grupo social relevante, ver: Pinch \& Bijker (1997).

${ }^{5}$ Anexo B do Tratado de Itaipu, publicado no Diário Oficial de 30 de agosto de 1973, p. 8645 apud COTRIM, 1999, p. 209.
} 
Revista Tecnologia e Sociedade, Curitiba, v. 11, n. 23, 2015

ISSN (versão online): 1984-3526

ISSN (versão impressa): 1809-0044

O problema foi deixado para um pouco depois" (MONTEIRO, 1999, pp. 38).

Em relatório preliminar elaborado no início de 1973, apoiado em nove apêndices que apresentavam os detalhes técnicos do projeto, constavam quatro estudos especiais, apresentados em relatórios separados (IECO; ILC, 1974a, p. I-2). Dentre eles, um era dedicado à diferença de frequência entre os sistemas de energia elétrica do Brasil e do Paraguai. Esse estudo baseava-se na previsão das necessidades do sistema paraguaio por um prazo de 20 anos, a partir do início da operação da usina, em 1982, e apresentava seis alternativas: 1) a conversão do sistema paraguaio de $50 \mathrm{~Hz}$ para $60 \mathrm{~Hz}$; 2) a instalação de seis geradores de 100 MW trabalhando em $50 \mathrm{~Hz}$, coaxiais com seis geradores de $700 \mathrm{MW}$ e $60 \mathrm{~Hz}$; 3) a instalação de sete geradores de $100 \mathrm{MW}$ de dupla frequência, $60 / 50 \mathrm{~Hz}$; 4) sete conversores rotativos de frequência de $100 \mathrm{MW}, 60 / 50 \mathrm{~Hz}$; 5) cinco conversores estáticos de frequência de $125 \mathrm{MW}, 60 / 50 \mathrm{~Hz}$, para operação back to back; 6) cinco conversores estáticos de frequência de $125 \mathrm{MW}, 60 / 50 \mathrm{~Hz}$, para operação back to back e operação dos circuitos de transmissão de corrente contínua (as alternativas 3 , 4, 5 e 6 incluíam geradores de 700 MW $60 \mathrm{~Hz})^{6}$ (DIRETORIA..., 2009, p. 2.34).

Para o Brasil, a solução mais viável em termos técnicos e econômicos correspondia à primeira alternativa, o que representava alterar todo o parque de máquinas industriais, equipamentos elétricos e aparelhos eletrodomésticos do país vizinho. A segunda melhor alternativa apontada pelo relatório corresponderia à instalação de sete unidades geradoras de $100 \mathrm{MW}, 60 / 50 \mathrm{~Hz}$. No entanto, admitia-se que o estudo não se preocupava com os problemas do sistema nas "etapas posteriores", o que significava "após 2003", quando a demanda de $50 \mathrm{~Hz}$ por parte do Paraguai poderia ser maior. $O$ engenheiro paraguaio e diretor-adjunto de Itaipu, Enzo Debernardi, por exemplo, argumentava que dentro de algumas dezenas de anos, a partir de sua industrialização, o Paraguai viria a utilizar "os 5 milhões de quilowatts de Itaipu" que the cabiam pelo tratado (CORDIALIDADE..., 1973, p. 20). Portanto, da mesma forma, a dificuldade para determinar com precisão o crescimento futuro no Paraguai, impedia a opção por uma instalação limitada de geração em $50 \mathrm{~Hz}$.

Assim, a projeção da demanda paraguaia por energia tinha peso fundamental,

\footnotetext{
${ }^{6}$ Neste momento dos estudos, as alternativas que previam a transmissão de corrente contínua a longa distância no Brasil não foram consideradas "porque a experiência mundial com grandes tiristores e transmissão de corrente contínua de alta tensão ainda era limitada e, por esse motivo, considerada de alto risco" (DIRETORIA..., 2009, p. 2.34).
} 
Revista Tecnologia e Sociedade, Curitiba, v. 11, n. 23, 2015

ISSN (versão online): 1984-3526

ISSN (versão impressa): 1809-0044

pois de acordo com o Tratado de Itaipu, a energia produzida pelo aproveitamento hidrelétrico do trecho do rio Paraná em questão, seria dividida em partes iguais entre os dois países, sendo reconhecido a cada um deles o direito de aquisição da energia que não fosse utilizada pelo outro país para seu próprio consumo (BRASIL; PARAGUAI, 1973). E com a conversão do Paraguai a $60 \mathrm{~Hz}$ sendo considerada politicamente inaceitável pelos relatórios técnicos (DIRETORIA..., 2009, p. 2.34), em novembro de 1973, foi estabelecido como critério para estudo a manutenção do sistema de $50 \mathrm{~Hz}$ no Paraguai e a simetria geral dos equipamentos, com a metade da capacidade de geração instalada em cada frequência. Este critério básico levou à investigação de três alternativas (Ibid, p. 2.34) 7 que contemplavam as duas frequências, considerando a demanda incerta de energia pelo Paraguai:

1. Conversão estática, back to back, de $50 \mathrm{~Hz}$ a $60 \mathrm{~Hz}$, envolvendo a metade da produção da central. 2 . Unidades de velocidade constante e dupla frequência para a metade da central que poderiam ser mudadas gradualmente de $60 \mathrm{~Hz}$ para $50 \mathrm{~Hz}$. 3. Unidades de duas velocidades para operar ou em $50 \mathrm{~Hz}$ ou em $60 \mathrm{~Hz}$ para a metade da central (Ibid, p. 2.34).

Estas opções implicavam no fato de que a energia produzida por Itaipu teria três fins diferentes: uma parte em $50 \mathrm{~Hz}$ para consumo no Paraguai, outra em $60 \mathrm{~Hz}$ para o Brasil e uma parte da energia que cabia ao Paraguai, mas que não consumida lá, seria vendida ao Brasil (LIMA, 2006, p. 252).

No final de 1973, foram estabelecidos os seguintes critérios para o estudo final de viabilidade de projeto que seria entregue em 1974: "Sistema de $50 \mathrm{~Hz}$ em 400 kV e 230 kV para o Paraguai; Sistema de $60 \mathrm{~Hz}$ em 750 kV para o Brasil; Metade da capacidade instalada seria de abastecimento variável para os sistemas de 50 e $60 \mathrm{~Hz}$, incluindo o ajuste preciso diante da demanda" (DIRETORIA..., 2009, p. 2.35).

O relatório final apresentado à Comissão Mista Técnica, em 1974 apontava que havia tempo antes da tomada de decisão final, permitindo assim que se "estudasse o desenvolvimento do equipamento de manobra de uma subestação isolada a gás GIS-SF6 de $500 \mathrm{kV}$ e os rápidos progressos no campo de transmissão de corrente contínua de alta tensão, os quais eventualmente justificariam uma reavaliação das alternativas possíveis" (DIRETORIA..., 2009, p. 2.36, grifo nosso).

Enquanto os estudos da Comissão Mista Técnica investiam no que havia de alternativa à mudança da frequência do país vizinho, diversas reuniões ocorriam

\footnotetext{
${ }^{7}$ Ver também IECO; ILC, 1974a, p. I-1.
} 
Revista Tecnologia e Sociedade, Curitiba, v. 11, n. 23, 2015

ISSN (versão online): 1984-3526

ISSN (versão impressa): 1809-0044

entre os representantes dos governos brasileiro e paraguaio, na tentativa de encontrar uma solução considerando a possibilidade de conversão da frequência paraguaia. Em 1977, o diretor geral da Itaipu Binacional afirmava: "Os dois governos precisam se definir sobre a ciclagem até julho", "Não podemos esperar mais para fazer as encomendas de equipamentos dentro dos prazos previstos" (FIM..., 1977, p. 28). Pelo lado paraguaio, Lima menciona um estudo realizado pela Ande, finalizado em 1977, com o objetivo de analisar as consequências da mudança da frequência no país, e que apresentou como pontos negativos o fato de não haver nenhuma superioridade na ciclagem $60 \mathrm{~Hz}$ em relação a de 50; o custo da troca, estimado em 76 milhões de dólares; o prazo de três anos para alteração de todo o sistema, além de uma série de danos irreversíveis aos usuários (LIMA, 2006, p.254).

$\mathrm{Na}$ imprensa brasileira a controvérsia começou a ocupar as páginas das revistas especialmente a partir de 1977. Nas negociações noticiadas, eram apresentadas propostas que colocavam a troca da alteração da frequência paraguaia por compensações e indenizações. Dentre elas estava o financiamento para a construção da barragem de Monday (DIFERENÇA..., 1980, p. 17; LIMA, 2006, p. 255), a construção de uma siderúrgica no Paraguai, a construção de uma ferrovia ligando Assunção ao Porto de Paranaguá, a outorga na facilidade para utilizar o sistema rodoviário brasileiro em direção à Montevidéu (CAUBET apud LIMA 2006, p. 255) e o pagamento, através de investimentos em planos de desenvolvimento, da responsabilidade financeira pela mudança e por meio de equipamentos bélicos, como uma esquadrilha de aviões Xavante e armamentos (SEM..., 1977, p. 24).

A principal associação de empresários do Paraguai na época, a Union Industrial Paraguaya (UIP), argumentava que os prejuízos econômicos que a alteração no sistema traria, eram da ordem de 400 milhões de dólares e que, portanto, não seriam adequadamente compensados pelo Brasil (Ibid, p. 21). Outra questão levantada pelos empresários da UIP era a de que a alteração tornaria o Paraguai um virtual "mercado cativo" da indústria brasileira em matéria de equipamentos elétricos e eletrodomésticos. Estes elementos, somados ao fato de que a alteração no sistema paraguaio comprometeria os projetos futuros entre Paraguai e Argentina, como as usinas de Corpus e de Yaceritá-Apipé, que também utilizariam geração em $50 \mathrm{~Hz}$, tocavam na questão da soberania paraguaia e da "penetração brasileira" no país vizinho, elementos que o próprio projeto de Itaipu já havia levantado. 
Revista Tecnologia e Sociedade, Curitiba, v. 11, n. 23, 2015

ISSN (versão online): 1984-3526

ISSN (versão impressa): 1809-0044

A análise dessas negociações na imprensa, frequentemente vinha acompanhada da observação daquilo que era entendido como a "diplomacia pendular" $^{8}$ do general Alfredo Stroessner, voltada a tirar o melhor proveito das rivalidades entre Brasil e Argentina.

\begin{abstract}
Para tomar a decisão de adaptar os 50 ciclos da corrente elétrica do Paraguai aos 60 utilizados no Brasil [...], Stroessner procurou tirar toda sorte de vantagens do governo brasileiro. Pedidos classificados de "estranhos" em Brasília foram feitos a Geisel em três encontros mantidos entre os dois presidentes. Irritado com as reivindicações, na noite do dia 9 de novembro Geisel convocou uma reunião de autoridades do setor energético e diplomático no Palácio da Alvorada, durante a qual foi decidida a instalação de geradores de 50 e de 60 ciclos em Itaipu. Transmitida a decisão para Assunção, Stroessner não teve outro remédio senão anunciar a manutenção da ciclagem paraguaia, apresentada como mais uma prova de seu "nacionalismo" (VEJA, 1978, p. 34).
\end{abstract}

Lima atribui o adiamento da decisão interna paraguaia à proximidade com o período eleitoral, pois se Alfredo Stroessner acatasse aquela que era considerada a melhor alternativa para o Brasil, poderia ser acusado de entreguista, o que prejudicaria a intenção de confirmar seu mandato em fevereiro de 1978 (2006, p. 256). $E$, de fato, nos momentos em que as negociações pareciam inclinar-se às intenções brasileiras, a UIP, grupo social de peso no Paraguai, manifestava-se decididamente a favor da manutenção dos 50 ciclos (PARAGUAI, 1978, p. 29).

Oficialmente, a decisão final foi tomada em novembro de 1977, após a realização de, pelo menos, duas reuniões em Brasília (PEIXES..., 1977, p. 28). Uma, que reuniu técnicos dos dois países, sendo os paraguaios liderados por Enzo Debernardi, e os brasileiros pelo embaixador João Hermes Pereira de Araújo, em que se definiu que o Paraguai não aceitaria a proposta brasileira de transformar seu mercado consumidor para o sistema de 60 ciclos; e outra, que contou com a presença do presidente Ernesto Geisel, do ministro Golbery do Couto e Silva, do ministro das relações exteriores, Azeredo da Silveira, do embaixador João Hermes e do presidente e do diretor de Planejamento da ELETROBRÁS, respectivamente Antônio Carlos Magalhães e Licínio Seabra, em que foi tomada a decisão de que o Brasil permitiria que a hidrelétrica de Itaipu gerasse energia em 60 e $50 \mathrm{~Hz}$ e ficaria por conta do Brasil a conversão para ciclagem conveniente ao seu mercado consumidor da parte paraguaia da energia produzida em $50 \mathrm{~Hz}$ (MONTEIRO, 1999,

\footnotetext{
8 "E, na quinta-feira da semana passada, ao iniciar-se na cidade fronteiriça de Puerto Stroessner uma reunião extraordinária da diretoria da Itaipu Binacional, tinha-se como absolutamente certo que Stroessner daria mais um passo crucial para fixar o pêndulo paraguaio definitivamente do lado brasileiro - a mudança da ciclagem da rede elétrica de seu país para 60 herz, a mesma do Brasil” (SOCIO..., 1977, p. 21).
} 
Revista Tecnologia e Sociedade, Curitiba, v. 11, n. 23, 2015

ISSN (versão online): 1984-3526

ISSN (versão impressa): 1809-0044

p. 40).

No início de 1978 a revista Veja anunciava que o governo brasileiro havia retirado a proposta de construção da usina Monday, o que era descrito como uma "represália" do governo brasileiro ao governo paraguaio "por ter contrariado os interesses brasileiros na questão da construção da Hidrelétrica de Itaipu, ao recusarse a alterar a frequência elétrica de seu país, após quase um ano de negociações" (PARAGUAI, 1978, p. 32) ${ }^{9}$.

A notícia ainda destacava as consequências da decisão brasileira, explicando que se a obra fosse realizada, teria auxiliado no enchimento da barragem de Itaipu, diminuindo o prejuízo argentino na vazão do rio Paraná e que, portanto, o Paraguai sairia prejudicado tanto em seu "relacionamento com o governo argentino", já que a ação tornava mais difíceis as soluções para o problema do aproveitamento hidrelétrico do rio Paraná, quanto por prejudicar os projetos da ditadura de Stroessner, de transformar o Paraguai em um dos "maiores exportadores de energia elétrica do mundo" (VEJA, 1978, p. 32).

Enquanto os governos dos dois países negociavam a alteração da frequência do sistema paraguaio, os estudos da Comissão Mista Técnica chegavam a um acerto final sobre determinados pontos técnicos da questão sobre como converter e transmitir a frequência de $50 \mathrm{hz}$ para o Brasil. Os estudos 10 investiram no desenvolvimento da subestação isolada a gás de 500 quilovolts (kV) e na transmissão de corrente contínua. As análises indicaram que a opção "permitiria eliminar os disjuntores de baixa tensão dentro da casa de força e reduzir o tamanho do pátio de manobra ao ar livre e o número de linhas de transmissão". A flexibilidade e fiabilidade de operação também seriam melhoradas com a disposição de uma só linha e foram apontados benefícios econômicos na transmissão a longa distância em corrente contínua de alta tensão em comparação com a instalação back to back (DIRETORIA..., 2009, p. 2.36). Dessa forma, o arranjo das subestações e do sistema de transmissão foram revisados de modo que, em 1978, chegou-se a um acordo geral sobre os seguintes pontos:

\footnotetext{
${ }^{9}$ A revista Veja afirmava que segundo um estudo brasileiro o lago de Itaipu formaria uma ligação com o rio Monday, e deste com o rio Acaray, todos correndo somente em território paraguaio, formando um potencial de quase 1,5 milhão de quilowatts exclusivos do Paraguai (1978, p 32).

${ }^{10}$ O relatório final de viabilidade de julho de 1974 (IECO; ILC, 1974b) havia incorporado os estudos realizados até junho daquele ano. A partir de então, além do último estudo, de 1975, acima citado, os registros apresentados no volume "Projeto Hidrelétrico de Itaipu" (2009) tratam apenas do estudo que deu origem ao arranjo definitivo, de 1978.
} 
Revista Tecnologia e Sociedade, Curitiba, v. 11, n. 23, 2015

ISSN (versão online): 1984-3526

ISSN (versão impressa): 1809-0044

Subestação de $500 \mathrm{kV}$ isolada a gás (GIS-SF6) seria instalada na casa de força; Transmissão em 500 kV, usando quatro linhas para cada setor de frequência, levaria a energia até as áreas das margens direita e esquerda; $750 \mathrm{kV}$ ca e $\pm 600 \mathrm{kV}$ cc seriam usados para transmissão no Brasil; $230 \mathrm{kV}$ ca e a futura linha de $500 \mathrm{kV}$ ca seriam usados para a transmissão no Paraguai (Ibid, p. 2.36).

Essa solução, com nove unidades geradoras de $50 \mathrm{~Hz}$ e nove de $60 \mathrm{~Hz}$, "não requeria dispositivos para mudar a frequência”. A energia iria para as duas margens a 500 quilovolts, em corrente alternada (ca). A energia em $60 \mathrm{~Hz}$ seria transmitida aos centros de consumo através de um sistema de corrente alternada em extra-alta tensão e a energia de $50 \mathrm{~Hz}$, para o Paraguai, seria reduzida inicialmente a 230 quilovolts em corrente alternada, "com previsão de transmissão a 500 kV ca no futuro". A maior parte da energia de $50 \mathrm{~Hz}$, que seria consumida no Brasil, seria transmitida a $500 \mathrm{kV}$ ca até a margem esquerda, até uma estação conversora que a transformaria em corrente contínua, que não tem frequência. Dessa forma ela seria transmitida para São Paulo em dois bipolos de aproximadamente 600 quilovolts (DIRETORIA..., 2009, p. 2.36; MONTEIRO, 1999, pp. 38-40). Antes das estações recebedoras, no ponto de destino, "seria construída uma outra estação conversora [em Ibiúna, São Paulo], que desta vez transformaria a corrente contínua em corrente alternada, agora em $60 \mathrm{~Hz}$, pronta para o consumo" (MONTEIRO, 1999, pp. 3840)11. O relatório apontou as seguintes vantagens sobre o arranjo:

\begin{abstract}
[...] a alternativa era politicamente aceitável para ambos os países; Maior flexibilidade por adequar-se ao futuro crescimento da utilização de energia no Paraguai; Sem restrições quanto às possíveis interconexões com outras nações vizinhas que geram em $50 \mathrm{~Hz}$; Maior flexibilidade para a determinação das características das turbinas e geradores apropriados para cada frequência; Para o Brasil, ganhar-se-ia experiência com a transmissão e conversão em HVDC, de grande utilidade em outras áreas, especialmente de transmissão desde as futuras hidrelétricas na Amazônia até os centros de consumo do país; Não apresentava dificuldades técnicas importantes; Apesar de não ser a solução de menor custo, a economia tanto no custo inicial como na eficiência das linhas de transmissão compensava parcialmente o custo da conversão e as perdas na conversão; (DIRETORIA ..., 2009, p. 2.36).
\end{abstract}

A adoção de determinados equipamentos em um tal arranjo, definindo a alternativa vencedora, traduziu as escolhas políticas de grupos limitados em uma disputa de interesses econômicos e políticos assimétricos. É fundamental considerar a multiplicidade e heterogeneidade dos elementos associados, bem como as

\footnotetext{
${ }^{11}$ A transmissão da energia gerada em Itaipu para o sistema interligado brasileiro ocorre, da subestação de Foz do Iguaçu, Paraná, através das empresas Furnas e Copel: "A energia em $50 \mathrm{~Hz}$ utiliza o sistema de corrente contínua de Furnas (Elo CC) e a energia em $60 \mathrm{~Hz}$ utiliza o sistema de $765 \mathrm{kV}$ de Furnas e o sistema de $525 \mathrm{kV}$ da Copel". Disponível em: <https://www.itaipu.gov.br/energia/integracao-ao-sistema-brasileiro>.
} 
Revista Tecnologia e Sociedade, Curitiba, v. 11, n. 23, 2015

ISSN (versão online): 1984-3526

ISSN (versão impressa): 1809-0044

interdependências e o acúmulo de técnicas e conhecimentos organizados. Nesse sentido, tanto a descrição do processo quanto a complexidade das relações que o constituem podem ser compreendidas a partir de diversas abordagens do campo CTS.

T. Hughes (1997) compreende em sua abordagem dos sistemas técnicos o papel dos interesses empresariais, a resposta dos usuários, a personalidade dos inventores, os artefatos físicos, os acordos entre autoridades políticas, assim como especificações técnicas. Assim, as controvérsias sobre a frequência de operação da usina de Itaipu, envolvem a atuação de empresas como a Ande e a Eletrobrás, as ditaduras brasileira e paraguaia, a Argentina, as características atribuídas aos dois governos, como a "diplomacia pendular" de Stroessner e o "imperialismo brasileiro", a pressão dos empresários paraguaios e os estudos das diversas alternativas. Estes, dentre outros elementos, surgem como aspectos interligados na construção do sistema de geração e distribuição de energia.

A reflexão, em termos de sistemas técnicos, coloca que as relações foram estabelecidas por meio de conflitos e divergências e aponta para o papel das negociações no alcance de uma resolução. É possível, portanto, compreender a resolução da controvérsia em torno da frequência de Itaipu enquanto um sistema técnico que atingiu seu momentum através da aceitação, por parte dos grupos e instituições relacionados, da alternativa eleita. A noção de momentum, proposta por Hughes(1997), possibilita compreender a projeção das características construídas no passado, no futuro, e discute não somente o desenvolvimento de artefatos físicos, capazes de gerar e transmitir energia para os consumidores, mas também formas organizacionais, como empresas de controle de serviços públicos e o estímulo ao investimento em hidreletricidade em regiões mais distantes dos centros de consumo.

A construção da linha de transmissão em corrente contínua é um exemplo de um novo tipo de conhecimento em transmissão para o Brasil, necessário para a condução de energia por longas distâncias, e que representava naquele momento a autonomia brasileira sobre a energia gerada em Itaipu e futuramente, o investimento em uma tecnologia fundamental para o aproveitamento hidrelétrico dos rios da bacia amazônica.

Estes acontecimentos integram-se à complexa interdependência que a implantação de hidrelétricas estabelece - e requer para sua execução -, com uma 
Revista Tecnologia e Sociedade, Curitiba, v. 11, n. 23, 2015

ISSN (versão online): 1984-3526

ISSN (versão impressa): 1809-0044

série de elementos de caráter político, econômico e cultural. Não se trata, portanto, de analisá-los somente em termos de "consequências" da construção das barragens, mas principalmente, de considerar o processo social tecnológico em que os objetos de análise dos dois artigos apresentados se inserem e se constituem. Conforme Thomas Hughes (1997), trata-se de observar a dinâmica dos sistemas, o que implica não apenas em consequências diretas da materialidade das hidrelétricas, mas também, em um constante trabalho de reprodução da operação do sistema, com a articulação de diversos fatores imateriais. Pesam, portanto, as mediações do poder distribuído desigualmente entre atores, sistemas e artefatos técnicos.

\section{CONSIDERAÇÕES FINAIS}

A interpretação do processo em sua dimensão histórica e social, demonstra que a escolha resulta da influência que os interesses sociais têm sobre o design e, consequentemente, sobre o desenvolvimento tecnológico. A alternativa que abriu as discussões no país vizinho teve significados distintos apontados pelos atores envolvidos ao longo do processo. Pelos empresários, temerosos com os custos e demais transtornos que a alteração de frequência representaria para o Paraguai, a alteração representaria "entreguismo" ao imperialismo brasileiro. Para o governo paraguaio, que demorou a tomar sua decisão, a alteração de frequência poderia tanto representar acordos futuros com o Brasil, mas também uma fissura na soberania do país. Para o Brasil, a mudança era a alternativa mais viável financeiramente e poderia significar mais um mercado consumidor para seus produtos. Adotar a alternativa que assumia os custos pela implantação de um sistema capaz de resolver o problema de conversão e transmissão do excedente de energia em $50 \mathrm{~Hz}$, também representou autonomia e o investimento em tecnologia que seria utilizada no futuro, evitando criar animosidades com os interesses dos dois países vizinhos.

Nesse sentido, é importante observar que os debates em torno da frequência em Itaipu tratam de controvérsias fechadas em um contexto de atores restritos, limitando as decisões às instâncias que não preveem participação pública. Nessa definição, o sistema adquiriu seu momentum, verificado na aceitação dos grupos envolvidos, no controle mais intenso que se estabelece em sua manutenção, com a 
Revista Tecnologia e Sociedade, Curitiba, v. 11, n. 23, 2015

ISSN (versão online): 1984-3526

ISSN (versão impressa): 1809-0044

criação de uma série de mecanismos de retroalimentação que colocaram um domínio sobre o ambiente.

Portanto, por mais que se observe a disputa entre Brasil e Paraguai em torno das questões de geração e distribuição e que os grupos hegemônicos articulem ideias de nacionalismo ao combaterem uma suposta exploração de um, pelo outro, a reflexão deve manter em vista as parcelas da sociedade excluídas do processo decisório em um contexto histórico de hegemonia autoritária, e que, de fato, tornamse exploradas dentro de cada um dos países.

\section{REFERÊNCIAS}

BRASIL; PARAGUAI. Anexo "B" do Tratado de Itaipu. Brasília, 1979. Disponível em: <http://goo.gl/AuKG9l>). Acesso em: 09 dez. 2013.

BRASIL; PARAGUAI. Tratado de Itaipu. Brasília, 26 abr. 1973. Disponível em: <http://goo.gl/6ZFR5y>. Acesso em: 09 dez. 2013.

CORDIALIDADE dos quilowatts (A). Revista Veja, São Paulo, Editora Abril, ed. 243, p. 20, 02 mai. 1973.

COTRIM, John R. Notas sobre os antecedentes da criação de Itaipu Binacional. Rio de Janeiro: Centro da Memória da Eletricidade no Brasil, 1999.

DIFERENÇA é Itaipu (A). Revista Veja, São Paulo, Editora Abril, ed. 606, p. 17, 16 abr. 1980.

DIRETORIA TÉCNICA DA ITAIPU BINACIONAL. Itaipu Usina Hidrelétrica - Projeto: Aspectos de engenharia. Foz do Iguaçu: Itaipu Binacional, 2009.

FEENBERG, Andrew. Racionalização Subversiva: Tecnologia, Poder e Democracia. In: NEDER, Ricardo T. A Teoria Crítica de Andrew Feenberg: Racionalização Democrática, Poder e Tecnologia.Brasília: Observatório do Movimento pela Tecnologia Social na América Latina / CDS / UnB /Capes, 2010.

FIM de conversa. Revista Veja. São Paulo, Editora Abril, ed. 480, p. 28, 16 nov. 1977.

HUGHES, Thomas P. The evolution of large technological systems. In: BIJKER, Wiebe E. et al (eds.). The social construction of technological systems: new directions in the sociology and history of technology. Cambridge, Mass.: MIT Press, 1997, p. 51-82.

IECO - International Engineering Co. Inc.; ELC - Electroconsult Spa. Estudo do Rio Paraná - Projeto Itaipu - Apêndice M (Alternativas para dupla frequência). 1974a .

1974b.

Estudo do Rio Paraná - Projeto Itaipu: Relatório Final de Viabilidade.

ITAIPU BINACIONAL. Aspectos técnicos do Empreendimento Itaipu. Rio de Janeiro, 1989.

ITAIPU: crítica tardia. Revista Veja, São Paulo, Editora Abril, ed. 403, p. 92, 26 mai. 1976. 
Revista Tecnologia e Sociedade, Curitiba, v. 11, n. 23, 2015

ISSN (versão online): 1984-3526

ISSN (versão impressa): 1809-0044

LIMA, Ivone T. C. de. Itaipu: as faces de um mega projeto de desenvolvimento (19301984). Germânica: Niterói, 2006.

MONTEIRO, Nilson. Itaipu, a luz. Curitiba: Itaipu Binacional, Assessoria de Comunicação Social, 1999.

PARAGUAI. Revista Veja, São Paulo, Editora Abril, ed. 493, p. 26-34, 15 fev. 1978.

PEIXES e usinas (De). Revista Veja, São Paulo, Editora Abril, ed. 450, p. 28, 20 abr. 1977.

PINCH, Trevor; BIJKER, Wiebe E. The social construction of facts and artifacts: or how the Sociology of Science and the Sociology of Technology might benefit each other. In: BIJKER, Wiebe E. et al (eds.). The social construction of technological systems: new directions in the sociology and history of technology. Cambridge, Mass.: MIT Press, 1997, p. 17-50.

REPRESÁLIA. Revista Veja, São Paulo, Editora Abril, ed. 489, p. 32, 18 jan. 1978.

SEM respostas. Revista Veja, São Paulo, Editora Abril, ed. 481, p. 24, 23 nov. 1977.

SÓCIO sintonizado (Um). Revista Veja, São Paulo, Editora Abril, ed. 464, p. 21-24, 27 jul. 1977.

SÓRIA, Miguel A. Z. Usina de Itaipu: Integração energética entre Brasil e Paraguai. Foz do Iguaçu: Itaipu Binacional, 2012.

THOMAS, Hernán. Estructuras cerradas versus processos dinámicos: trayectorias y estilos de innovación y cambio tecnológico. In: BUCH, Alfonso; THOMAS, Hernán. Actos, actores y artefactos: sociología de la tecnología. Bernal. Universidad Nacional de Quilmes Editorial, 2008, p. 217-262. 